\title{
RELATO DE EXPERIENCIAS INICIAIS DO PRJETO DE EXTENSÃO ANTONIO GRAMSCI, UNIVALI, SC.
}

\author{
Murilo Lyra Pinto' \\ Marcos Rodrigo Rita ${ }^{2}$ \\ Nerilaine Lasch $^{3}$ \\ Rafael Thiago Laurentino ${ }^{4}$ \\ Tirza Oliveira Cruz ${ }^{5}$ \\ David Rivero Tames ${ }^{6}$ \\ Marco Aurelio da Ros $^{7}$ \\ Rita de Cássia Gabrielli Souza Lima ${ }^{8}$
}

Resumo: O objetivo deste artigo é relatar as experiências iniciais vivenciadas, em 2015, pelo Projeto de Extensão Antonio Gramsci: fomentando a concepção ativista de educação, da Universidade do Vale do Itajaí, SC. A abordagem dialética foi adotada como método e matriz epistêmica. Na oficina-base do Projeto, intitulada Universidade, os extensionistas foram instigados para responder qual o papel da Universidade e que papel a Universidade deveria ter na sociedade brasileira. A sintese dos questionamentos deu-se na interlocução entre transformação, vontade coletiva e participação. Ancorados em Antonio Gramsci, concluíram que a produção de trabalhadores reflexivos e críticos para o Sistema Único de Saúde (SUS) exige o caráter orgânico na formação acadêmica e que a vontade coletiva é uma atividade ético-política. A execução deste Projeto expressa a natureza pública da Instituição e seu compromisso com o desenvolvimento humano.

Palavras-chave: Extensão universitária; Formação histórica ético-política; Educação popular; Sistema Único de Saúde.

\footnotetext{
${ }^{1}$ Curso de Nutrição/Universidade do Vale do Itajaí (UNIVALI), Brasil. E-mail: mu.lyra@gmail.com.

${ }^{2}$ Curso de Odontologia/UNIVALI, Brasil. E-mail: marcosritasjb@hotmail.com.

${ }^{3}$ Curso de Odontologia/UNIVALI, Brasil. E-mail: neri lasch@hotmail.com.

${ }^{4}$ Curso de Odontologia/UNIVALI, Brasil. E-mail: rafaelthiagol@hotmail.com.

${ }^{5}$ Curso de Odontologia/UNIVALI, Brasil. E-mail: tirzinha_164@hotmail.com.

${ }^{6}$ Curso de Odontologia/UNIVALI, Brasil. E-mail: dtames@univali.br.

${ }^{7}$ Curso de Medicina/UNIVALI, Brasil. E-mail: ros@univali.br.

${ }^{8}$ Curso de Odontologia/UNIVALI, Brasil. E-mail: rita.lima@univali.br.
} 